\title{
Social and Environmental Determinants of Community-Acquired Antimicrobial-Resistant Escherichia coli in Children Living in Semirural Communities of Quito, Ecuador
}

\author{
Kathleen M. Kurowski, ${ }^{1}$ Rachel Marusinec, ${ }^{1}$ Heather K. Amato, ${ }^{1}$ Carlos Saraiva-Garcia, ${ }^{2}$ Fernanda Loayza, ${ }^{2}$ Liseth Salinas, ${ }^{2}$ \\ Gabriel Trueba, ${ }^{2}$ and Jay P. Graham ${ }^{1 *}$ \\ ${ }^{1}$ University of California, Berkeley School of Public Health, Berkeley, California; ${ }^{2}$ Instituto de Microbiología, Colegio de Ciencias Biológicas y \\ Ambientales, Universidad San Francisco de Quito, Quito, Ecuador
}

\begin{abstract}
Extended-spectrum beta-lactamase-producing Enterobacteriaceae (ESBL), a family of bacteria that includes Escherichia coli, have emerged as a global health threat. This study examined risks associated with carriage of thirdgeneration cephalosporin-resistant (3GC-R) E. coli, including ESBL-producing, multidrug-resistant, and extensively drugresistant (XDR) strains in children living in semirural parishes of Quito, Ecuador. We conducted a longitudinal study with two cycles of sampling $(N=374, N=366)$ that included an analysis of child fecal samples and survey questions relating to water, sanitation, and hygiene, socioeconomic status, household crowding, and animal ownership. We used multivariate regression models to assess risk factors associated with a child being colonized. Across the two cycles, $18.4 \%(n=516)$ of the 3GC-R isolates were ESBL-producing E. coli, and 40.3\% $(n=516)$ were XDR E. coli. Children living in households that owned between 11 and 20 backyard animals had an increased odds of being colonized with XDR E. coli (odds ratio [OR] $=$ 1.94, 95\% confidence interval [Cl]: 1.05-3.60) compared with those with no animals. Households that reported smelling odors from commercial poultry had increased odds of having a child positive for XDR $E$. coli $(\mathrm{OR}=1.72,95 \% \mathrm{Cl}$ : 1.11-2.66). Our results suggest that colonization of children with antimicrobial-resistant $E$. coli is influenced by exposure to backyard and commercial livestock and poultry. Future studies should consider community-level risk factors because child exposures to drug-resistant bacteria are likely influenced by neighborhood and regional risk factors.
\end{abstract}

\section{INTRODUCTION}

Antimicrobial resistance (AMR), especially among Enterobacteriaceae, is a significant global health challenge that is leading to increases in morbidity and mortality. ${ }^{1,2}$ The WHO and the U.S. Centers for Disease Control and Prevention have identified extended-spectrum $\beta$-lactamase producing Enterobacteriaceae (ESBL-E) - a family of bacteria that includes Escherichia coli and Klebsiella pneumoniae-as a serious threat to public health. ${ }^{3}$ ESBL-E confer resistance to a broad spectrum of $\beta$-lactam antimicrobials used to treat a variety of bacterial infections. The global prevalence of ESBL-E is increasing, with carrier rates being as high as $50 \%$ in some parts of the world. ${ }^{4,5}$ Studies have shown that ESBL-E are no longer limited to individuals in clinical settings but are also present in community settings. ${ }^{6,7}$ Outside of a clinical setting, international travel is one such way that resistance can be disseminated around the world. ${ }^{8-10}$ Although travel to certain low- and middle-income countries (LMICs) has been shown to put travelers at risk for carriage of ESBL$E$, it is less clear which specific exposures within those countries and their full-time residents may augment risk. ${ }^{8,11}$

Dissemination of ESBL-E throughout communities may be driven by numerous social and environmental factors. ${ }^{11,12}$ The use of antimicrobials in food-animal production may also be an important driver for the development and spread of AMR in communities. ${ }^{13-15}$ Additionally, the presence of antimicrobial-resistant bacteria in waterways contaminated by human wastewater ${ }^{16}$ as well as waste from food-animal operations may also increase the risk that humans will be exposed. ${ }^{17}$ Other factors, such as visiting health care facilities, increased population densities, migration, and tourism, have

\footnotetext{
*Address correspondence to Jay P. Graham, Division of Environmental Health Sciences, University of California, Berkeley School of Public Health, 2121 Berkeley Way, Room 5302
} Berkeley, CA 94720-7360. E-mail: jay.graham@berkeley.edu also been shown to affect the prevalence of AMR in the community. ${ }^{5,11-13,16,18-21}$ The relationships of poverty, crowding, water, sanitation, and hygiene (WaSH) to AMR in the community, however, are not well understood. Studies have examined the relationship between antimicrobialresistant bacteria and poverty, as well as $\mathrm{WaSH}$, but not in a community-level setting. Nadimpali et al. examined antimicrobial resistance in urban informal settlements and the relationship that poverty has with antimicrobial resistance; they identified the relationship between WaSH and AMR as a gap in the research. ${ }^{22}$ Ramay et al. found that improving household hygiene was associated with a reduction in detection of AMR in low-income communities in Guatemala. ${ }^{23}$

The goal of this study was to identify social and environmental factors associated with ESBL-producing and multidrugresistant (MDR) E. coli carriage among young children in semirural parishes of Quito, Ecuador. We chose to focus on ESBL-producing and MDRE. coli because these types of bacteria are a major threat in South American countries. ${ }^{13}$ Our a priori hypotheses were that low socioeconomic status (SES), low education, poor WaSH, household crowding, and increased exposure to domestic animals would be associated with children being colonized with 3GCR E. coli.

\section{MATERIALS AND METHODS}

Study design and location. The study was carried out in six semirural parishes east of Quito, Ecuador: Checa, El Quinche, Pifo, Puembo, Tumbaco, and Yaruquí. Households were enrolled if they met the following inclusion criteria: 1) households with primary childcare provider present and over age 18 years or legally emancipated, 2) a child present in the household between age 6 months to 5 years, and 3) informed consent was provided by a primary childcare provider to participate in the study. Three-hundred and seventy-four households (cycle 1) and 366 households (cycle 2) were recruited and enrolled. Children under age 5 years were selected 
because they often reside in the home environment during the week, often play on the ground, and have been shown to be exposed to fecal bacteria in the household environment. ${ }^{24}$

On the first visit, between July 2018 to November 2018, stool samples were collected from the 374 children enrolled in the study, and at the second visit 6 months later between January 2019 to May 2019, 366 children were enrolled and sampled. Loss to follow-up occurred when families had moved, opted out of the study, or were not available for sample collection. In these cases, new households were enrolled.

Household survey. Caregivers were asked to participate in a survey once per cycle to assess a variety of demographic characteristics and risk factors. In addition to demographic information, survey questions measured level of education and asset ownership as an indicator of wealth. Questions assessing WaSH characteristics included information on the main sources of drinking water, if and how drinking water was treated, toilet facilities in the household, and handwashing habits. Additional questions were used to assess the proximity to commercial poultry or livestock operations, animal ownership (both livestock and pets) and contact, as well as the frequency of daycare attendance of children in the household. Crowding-related variables (household size, number of children under 12 living in the house, number of people per room) were assessed. Age was only collected for the respondent and for the child enrolled in the study.

Sample collection. Similar to our previous research methods, caregivers provided a fecal sample for a single child under 5 years of age enrolled in the study once per cycle. ${ }^{25}$ Stool samples were collected by the child's primary caretaker. Caretakers were instructed orally to cover the inside of the diaper with a clean plastic lining for infants. For older children, caretakers were given a fecal collection container and a plastic liner to place under the toilet seat to catch the stool. Caretakers were instructed to double-bag the sample container and keep it in the refrigerator until field staff could pick up the sample the same morning. Fecal samples were transported in a cooler $\left(\sim 4^{\circ} \mathrm{C}\right)$ to the laboratory and processed within 8 hours of collection.

3GC-R E. coli isolation. Fecal samples were streaked onto MacConkey agar with ceftriaxone $\left(2 \mathrm{mg} / \mathrm{mL}^{26}\right)$ and incubated at $37^{\circ} \mathrm{C}$ for 18 hours. After 18 hours, up to five lactose positive colonies were selected based on morphologic characteristics. ${ }^{26-28}$ Putative 3GC-R E. coli isolates were preserved in tryptic soy broth with $20 \%$ glycerol at $-80^{\circ} \mathrm{C}$. Two isolates per sample were randomly selected from available isolates and reconstituted on MacConkey agar at $37^{\circ} \mathrm{C}$ for 24 hours in preparation for evaluation of antimicrobial susceptibility by Kirby Bauer disk diffusion method. Colonies were also transferred to Chromocult ${ }^{\circledR}$ Coliform agar (Merck KGaA, Darmstadt, Germany) to further confirm their identification as $E$. coli. $^{25,29}$ Approximately $10 \%$ of $E$. coli isolates were also confirmed with API RapiD-20E to ensure proper speciation. ${ }^{27}$

Antimicrobial susceptibility testing. 3GC-R E. coli isolates for each child from cycle 1 and 2 were streaked on Mueller-Hinton agar for antimicrobial susceptibility testing at same time they were plated on with Chromocult $₫$ Coliform agar. Results were evaluated according to resistance or susceptibility interpretation criteria from 2018 Clinical and Laboratory Standards Institute (CLSI) guidelines. ${ }^{30} \mathrm{E}$. coli ATTC 25922 was used as a quality control strain, a negative control for presumptive 3GC-R E. coli isolates. Control plates with no
E. coli were used as a negative control to ensure plate sterility. Twelve antimicrobials from seven classes used for susceptibility testing included: cefazoline (CZ; $30 \mu \mathrm{g}$; first-generation cephalosporin), ampicillin (AM; $30 \mu \mathrm{g}$; penicillin), gentamicin (GM; $30 \mu \mathrm{g}$; aminoglycoside), Imipenem (IMP; $30 \mu \mathrm{g}$; carbapenem), ceftazidime/clavulanic acid (CAZ-CLA; 30/10 $\mu \mathrm{g}$; third-generation cephalosporin/beta-lactase inhibitor), trimethoprim-sulfamethoxazole (SXT; 1.25/23.75 $\mu \mathrm{g}$; sulfonamides), ceftazidime (CAZ; $30 \mu \mathrm{g}$; third-generation cephalosporin), cefepime (FEP; $30 \mu \mathrm{g}$; fourth-generation cephalosporin), ciprofloxacin (CIP; $5 \mu \mathrm{g}$; fluoroquinolone), amoxicillin/clavulanic acid (AMC; 20/10 $\mu$; penicillin/betalactamase inhibitor), cefotaxime (CTX; $30 \mu \mathrm{g}$; thirdgeneration cephalosporin), and tetracycline (TE; $30 \mu$; tetracycline). MDR was classified as resistance to three or more classe of antimicrobials of the seven classes tested. We classified extensively drug resistant (XDR) as resistance to five or more classes of antimicrobials of the seven classes tested. The combination disk approximation test was used with CAZ and CAZ/CLA, as outline in CLSI and EUCAST, to identify ESBL-producing $E$. coli. ${ }^{30-32}$ Results from the two isolates tested per child were combined into a single data point per child per cycle.

Statistical analyses. We measured associations between ESBL-producing $E$. coli and 10 social and environmental risk factors for AMR. A wealth index was constructed from a set of variables indicating asset ownership via principal component analysis (PCA) for each cycle. ${ }^{33,34}$ The following asset items were included in the wealth index: car, television, cable television, computer, Internet, house, and land. Wealth scores for the first principal component were broken up into tertiles to create high, medium, and low wealth categories. Exposures and outcomes were assessed at each of the two time points. The primary outcome of this study was whether a child carried at least one ESBLE. coli isolate at either time point. Secondary outcomes were whether a child carried at least one MDR $E$. coli isolate at each single time point or at least one XDR $E$. coli isolate at each single time point.

Univariate and multivariate logistic regression models were created for each exposure of interest, adjusting for confounding variables (Supplemental Table 1) determined a priori using existing literature and directed acyclic graphs (Supplemental Figure 1). The analysis of the data measured associations between exposure and outcome at each time point. We used generalized estimating equations (GEE) with robust standard errors and an exchangeable working correlation to adjust for repeated measures and unbalanced data. ${ }^{35}$ Unadjusted and adjusted odds ratios (ORs) were calculated for each exposure of interest. Analyses were performed using RStudio (version 1.2.1335; RStudio, PBC). We defined statistical significance as $P<0.05$ or the null value outside of the $95 \%$ confidence interval $(\mathrm{Cl})$.

The study protocol was approved by the Bioethics Committee at the Universidad San Francisco de Quito (\#2017-178M), the Ecuadorian Health Ministry (\#MSPCURI000243-3), and the Committee for Protection of Human Subjects at the University of California Berkeley (\#2019-02-11803).

\section{RESULTS}

Household characteristics. Table 1 describes the demographic characteristics of the 374 households enrolled in cycle 
1 and the 366 households enrolled in cycle 2. Two-hundred and ninety-six households participated in both cycle 1 and cycle 2 of the study. Seventy-eight households only participated in cycle 1 , and 70 households only participated in cycle 2. Roughly three-quarters of the respondents (i.e., primary caregivers) were under age 35 years, and the majority were female. Children enrolled in the study ranged from 6 months to 5 years old, with a median age of 2.01 years. Most households reported one to three children under 12 years in the home, and nearly two-thirds of households had four to six total household members.

WaSH and socioeconomic household characteristics are reported in Table 2. In cycle 1, approximately one-third of

TABLE 1

Child and household demographics in study population by data collection cycle

\begin{tabular}{|c|c|c|}
\hline & $\begin{array}{c}n(\%) \\
\text { Cycle } 1\end{array}$ & $\begin{array}{c}n(\%) \\
\text { Cycle } 2\end{array}$ \\
\hline Respondent age, years & $N=372$ & $N=365$ \\
\hline$<35$ & $286(76.7)$ & $275(75.3)$ \\
\hline $36-55$ & 79 (21.2) & $82(22.5)$ \\
\hline 56 & $6(1.6)$ & $8(2.2)$ \\
\hline Respondent sex & $N=372$ & $N=365$ \\
\hline Female & 344 (92.5) & $333(91.2)$ \\
\hline Male & $20(5.4)$ & $32(8.8)$ \\
\hline Ethnic group & $N=367$ & $N=365$ \\
\hline Mestizo & $329(89.6)$ & $342(93.7)$ \\
\hline Indigenous & $18(4.8)$ & $11(3.0)$ \\
\hline Other* & $27(7.2)$ & $10(2.7)$ \\
\hline Household size & $N=374$ & $N=366$ \\
\hline 1-3 people & $93(24.9)$ & $84(23.0)$ \\
\hline 4-6 people & $247(66.0)$ & $246(67.2)$ \\
\hline$\geq 7$ people & $34(9.1)$ & $36(9.8)$ \\
\hline $\begin{array}{l}\text { Children under } 12 \text { years } \\
\text { per household, } n\end{array}$ & $N=374$ & $N=366$ \\
\hline $0-2$ & $326(87.2)$ & $307(83.9)$ \\
\hline $3-4$ & $44(11.8)$ & $58(15.8)$ \\
\hline 5-7 children & $4(1.0)$ & $1(0.3)$ \\
\hline $\begin{array}{l}\text { Age of child enrolled } \\
\text { in study, years }\end{array}$ & $N=373$ & $N=366$ \\
\hline$<1$ & $66(17.7)$ & $40(10.9)$ \\
\hline 1 & 119 (31.9) & $122(33.3)$ \\
\hline 2 & $76(20.4)$ & 77 (21.0) \\
\hline 3 & 63 (16.9) & 65 (17.8) \\
\hline 4 & $49(13.1)$ & $60(16.4)$ \\
\hline 5 & $0(0)$ & $2(0.05)$ \\
\hline $\begin{array}{l}\text { Child received medical } \\
\text { treatment in past } 3 \text { months }\end{array}$ & $N=371$ & $N=365$ \\
\hline Yes & 117 (31.5) & $99(27.1)$ \\
\hline No & $254(68.5)$ & $366(72.9)$ \\
\hline $\begin{array}{l}\text { Child had diarrhea in } \\
\text { previous } 7 \text { days }\end{array}$ & $N=372$ & $N=365$ \\
\hline Yes & 76 (20.4) & $77(21.1)$ \\
\hline No & 296 (79.6) & $288(78.9)$ \\
\hline $\begin{array}{l}\text { Child took antibiotics } \\
\text { in past } 3 \text { months }\end{array}$ & $N=372$ & $N=362$ \\
\hline Yes & 275 (73.9) & $296(81.8)$ \\
\hline No & $97(26.1)$ & 66 (18.2) \\
\hline Animal ownership & $N=373$ & $N=366$ \\
\hline Yes & $238(63.8)$ & $246(67.2)$ \\
\hline No & $135(36.2)$ & $120(32.8)$ \\
\hline No. of animals per household & $N=374$ & $N=365$ \\
\hline 0 & $140(37.4)$ & $120(32.9)$ \\
\hline $1-10$ & $161(43.0)$ & $171(46.8)$ \\
\hline $11-20$ & $25(6.7)$ & $40(11.0)$ \\
\hline $21-30$ & $17(4.5)$ & $11(3.0)$ \\
\hline $31-40$ & $14(3.7)$ & 7 (1.9) \\
\hline $41-50$ & $1(0.27)$ & $6(1.6)$ \\
\hline$>50$ & $16(4.3)$ & $10(2.7)$ \\
\hline
\end{tabular}

the population fell into each wealth category: high wealth (34.5\%), medium wealth (30.5\%), and low wealth (35.0\%). In cycle 2, which included the enrollment of 70 new households, nearly half of the households fell into the medium wealth category. Most caregivers had at least a high school level education. Water and sanitation infrastructure was present at high levels across all households. Households mainly use piped water into their homes as their main source of drinking water, with about half reporting drinking water treatment before consumption (primarily by boiling). Nearly all homes had a flush toilet that emptied into the sewer.

Two-thirds of the households were classified as low crowding, defined as $\leq 2.5$ people per room. Nearly $80 \%$ of households did not detect odors from poultry operations, and $~ 84 \%$ had no knowledge of food-animal operations nearby. Twothirds of households reported owning backyard animals and pets, with nearly half owning 1 to 10 animals and less than $20 \%$ owning more than 20 animals.

E. coli susceptibility patterns. A total of 516 isolates from 444 households were confirmed to be 3GC-R E. coli from the child fecal samples and were included in the analysis. Table 3 describes 3GC-R E. coli susceptibility patterns among all of the child 3GC-R E. coli isolates analyzed. The 3GC-R isolates from both cycles were most commonly resistant to cefazoline, a first-generation cephalosporin (99.8\%), ampicillin (99.4\%), and cefotaxime, a third-generation cephalosporin (93.6\%). If an $E$. coli isolate is resistant to ceftriaxone, it can be considered resistant to cefotaxime as well. However, this does not happen with all isolates. According to CLSI guidelines, the prediction of resistance to ceftriaxone and cefotaxime was observed in $95 \%$ of the isolates tested, but the guidelines also say that this prediction can vary from $3 \%$ to $10 \%$ on a large population of bacteria tested. ${ }^{30}$ Virtually all isolates were susceptible to imipenem ( $<1 \%$ resistant), a last-line antimicrobial. Of all 3GC-R isolates tested across the two cycles, $18.4 \%$ were found to be ESBL-producing E. coli, and approximately $40 \%$ were found to be extensively drug-resistant $E$. coli. Individual drug-resistance patterns of 3GC-R isolates were consistent across the two cycles of sampling.

Risk factors for the presence of antimicrobial-resistant E. coli. Adjusted ORs suggested that animal ownership and household crowding may be associated with all antimicrobial-resistant outcomes (ESBL, MDR, XDR). Interestingly, we observed that medium and high-wealth groups were associated with lower odds of all outcomes, compared with low-wealth groups, although these relationships were not significant (Tables 4 and 6). The odds of ESBL E. coli carriage increased with decreasing levels of caregiver education, although this trend was not statistically significant (Table 4). Animal ownership and household crowding were also associated with near-significant increases in odds of ESBL E. coli carriage, with associations becoming stronger after adjusting for confounding variables (Table 4). Overall, however, there were no statistically significant associations between the exposure variables and ESBL $E$. coli carriage.

In univariate analyses, a low score on the wealth index was associated with decreased odds of MDR E. coli (OR: 0.674, 95\% Cl: 0.455-0.999) (Table 5). This association was not significant in multivariate models but still trended in the same direction (Table 6). Caregivers with only a high school education level had two times the odds (OR: 2.03, 95\% Cl: 1.01-4.11) of XDR E. coli carriage compared with caregivers 
with postsecondary education in univariate analysis (Table 5), although this association was no longer statistically significant after adjusting for potential confounding variables (Table 6). Reported odors due to poultry operations and ownership of 11 to 20 animals were significantly associated with XDR $E$. coli carriage in both univariate and multivariate models. Adjusting for confounding, reported odors due to poultry operations was associated with a $72 \%$ increase in the odds of XDR E. coli carriage (OR: $1.72,95 \% \mathrm{Cl}: 1.11-2.66)$, and ownership of 11 to 20 animals was associated with a $94 \%$ increase in the odds of XDR E. coli carriage (OR: 1.94, 95\% Cl: 1.05-3.60) (Table 6).

\section{DISCUSSION}

In this study, we observed a statistically significant association between animal ownership (11-20 animals) and presence of XDR E. coli in child fecal samples, as well as a statistically significant association between the respondent reporting to smell commercial poultry operations and presence of XDR E. coli. Recent literature has highlighted the importance of animal feces in WaSH programs and suggested that a more inclusive definition of $\mathrm{WaSH}$ is needed, one that incorporates

A Child positive for ESBL-E. coli

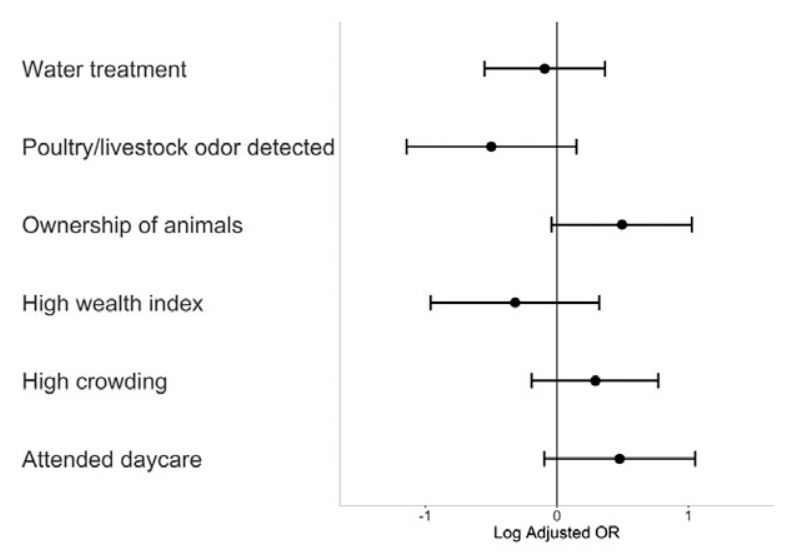

animals. Thus, we examined animal-related variables in this study. ${ }^{36}$ Antimicrobial use for both commercial and smallscale, or "backyard," poultry production is common in Ecuador, where antimicrobials are readily available over the counter and could drive selection for antimicrobial-resistant bacteria among animals in the study site. ${ }^{37}$ Animal ownership and presence of animals in the household could increase child contact with animal feces, and children are often exposed to fecal matter in the household environment via ingestion of soil and exploratory behavior. ${ }^{24}$ Increased contact with animal feces through oral ingestion could therefore lead to an increase in AMR in exposed children. Children are central to transmission of AMR between household members due to their high oral exposure to fecal-contaminated soil and their close contact with caregivers.

Reported detection of odor from commercial poultry operations and carriage of an XDR E. coli isolate were significantly associated in this study. The association between reported detection of odor and ESBL $E$. coli was not significant but did trend in the opposite direction as XDR and MDR. This could potentially be due to small sample size for ESBL $E$. coli. Odor was used as a proxy variable for proximity to poultry operations following a previous study that examined farm odor

\section{B Child positive for MDR E. coli}

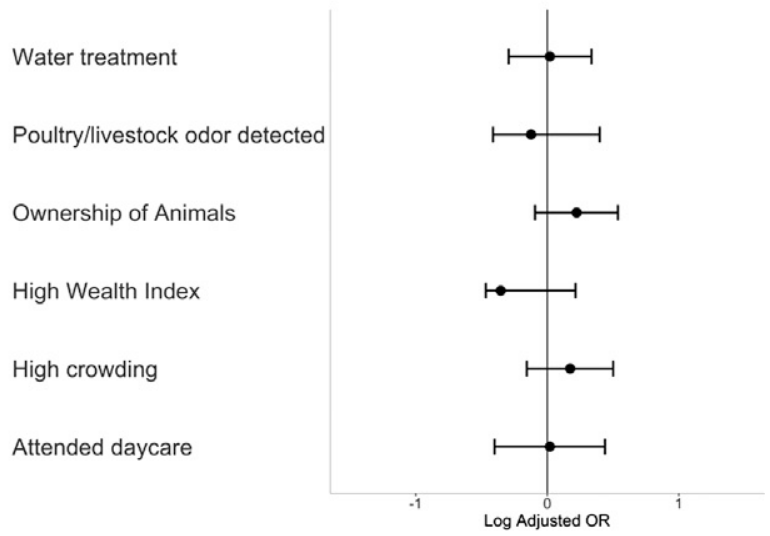

C Child positive for XDR E. coli

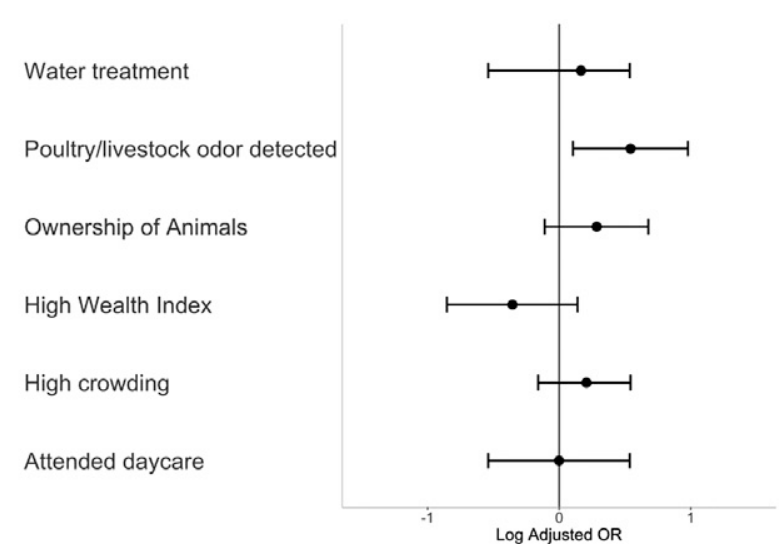

FIGURE 1. Adjusted log odds ratios (ORs) of key exposures of interest and Enterobacteriaceae (ESBL), multidrug resistant (MDR), and extensively drug resistant (XDR) Escherichia coli. (A) Each dot represents the log OR for the presence of ESBL E. coli in a child; lines indicate 95\% confidence intervals (Cls). (B) Each dot represents the log OR for presence of MDR E. coli; in a child; lines indicate 95\% Cls. (C) Each dot represents the log OR for presence of XDR $E$. coli in a child; lines indicate $95 \%$ Cls. 
TABLE 2

Child and household water, sanitation, and hygiene (WaSH) and socioeconomic status (SES) characteristics in study population by data collection cycle

\begin{tabular}{|c|c|c|}
\hline \multirow[b]{2}{*}{ WASH } & \multicolumn{2}{|c|}{$n(\%)$} \\
\hline & Cycle 1 & Cycle 2 \\
\hline Main source of drinking water & $N=374$ & $N=365$ \\
\hline Piped into house & $323(86.3)$ & $343(93.4)$ \\
\hline Bottled & $6(1.6)$ & $18(4.9)$ \\
\hline Other* & $45(12.0)$ & $4(1.1)$ \\
\hline Treatment of drinking water before consumption & $N=374$ & $N=366$ \\
\hline Yes & $181(48.4)$ & $193(52.7)$ \\
\hline No & $193(51.6)$ & $173(47.3)$ \\
\hline Method of water treatment & $N=178$ & $N=192$ \\
\hline Boiling & $159(89.3)$ & $157(81.8)$ \\
\hline Othert & $19(10.7)$ & $35(18.2)$ \\
\hline Toilet facility & $N=374$ & $N=364$ \\
\hline Toilet that goes into sewer & $352(94.1)$ & $351(96.4)$ \\
\hline Other $\ddagger$ & $22(5.9)$ & $13(3.6)$ \\
\hline Daycare attendance & $N=374$ & $N=365$ \\
\hline Yes & $52(13.9)$ & $84(23.0)$ \\
\hline No & $322(86.1)$ & $281(76.9)$ \\
\hline Crowding (average number of people per room) & $N=370$ & $N=364$ \\
\hline Low $(0-2.5)$ & $230(62.2)$ & $244(67.0)$ \\
\hline High (2.5-8) & $140(37.8)$ & $120(33.0)$ \\
\hline Detect odor from commercial poultry/livestock & $N=369$ & $N=366$ \\
\hline Yes & $81(22.0)$ & $79(21.6)$ \\
\hline No & $288(78.0)$ & $287(78.4)$ \\
\hline Knowledge of poultry operation nearby & $N=369$ & $N=364$ \\
\hline Yes & $62(16.8)$ & $56(15.4)$ \\
\hline No & 307 (83.2) & $308(84.6)$ \\
\hline \multicolumn{3}{|l|}{ Socioeconomic class } \\
\hline Caregiver education level & $N=371$ & $N=362$ \\
\hline Elementary school & $91(24.5)$ & $93(25.7)$ \\
\hline High school & $245(66.0)$ & $227(62.7)$ \\
\hline University/college & $35(9.4)$ & $42(11.6)$ \\
\hline Wealth index score & $N=374$ & $N=366$ \\
\hline Low & $129(34.5)$ & $120(32.8)$ \\
\hline Medium & $114(30.5)$ & $193(52.7)$ \\
\hline High & $131(35.0)$ & $53(14.5)$ \\
\hline
\end{tabular}

*Other included drinking water in courtyard, public key, well or protected spring, surface water.

† Other included filtering, chlorine/lime treatment, hovering in a cloth, leaving it to settle.

$\ddagger$ Other included as septic toilet, toilet with cistern, toilet (but unaware where it goes), latrine with hard floor and ventilation, latrine without hard floor, in free field.

TABLE 3

Phenotypic antimicrobial resistance of $3 \mathrm{GC}-\mathrm{R}$ Escherichia coli isolates* from children enrolled in the study

\begin{tabular}{|c|c|c|c|}
\hline \multirow[b]{2}{*}{ Antimicrobial } & \multicolumn{2}{|c|}{ No. and $\%$ of resistant isolates } & \multirow[b]{2}{*}{ Total $(N=516)$} \\
\hline & Cycle $1(N=277)$ & Cycle $2(N=239)$ & \\
\hline Cefazoline & $277(100.0)$ & $238(99.6)$ & $515(99.8)$ \\
\hline Ampicillin & $275(99.3)$ & 238 (99.6) & $513(99.4)$ \\
\hline Gentamicin & $47(17.0)$ & $47(19.7)$ & $94(18.2)$ \\
\hline Imipenem & $2(0.72)$ & 1 (0.42) & $3(0.58)$ \\
\hline Trimethoprim-sulfamethoxazole & $185(66.8)$ & $157(65.7)$ & $342(66.3)$ \\
\hline Ceftazidime & $72(26.0)$ & 58 (24.3) & $130(25.2)$ \\
\hline Cefepime & $121(43.7)$ & $106(44.4)$ & $227(44.0)$ \\
\hline Ciprofloxacin & 137 (49.5) & $118(49.4)$ & $255(49.4)$ \\
\hline Amoxicillin/clavulanic acid & $63(22.7)$ & $43(18.0)$ & $106(20.5)$ \\
\hline Cefotaxime & $256(92.4)$ & $227(95.0)$ & $483(93.6)$ \\
\hline Tetracycline & 201 (72.6) & 187 (78.2) & $388(75.2)$ \\
\hline ESBL+ & $52(18.8)$ & $43(18.0)$ & $95(18.4)$ \\
\hline ESBL- & $225(81.2)$ & 196 (82.0) & $421(81.6)$ \\
\hline MDR & $231(83.4)$ & $217(90.8)$ & $448(86.8)$ \\
\hline XDR $\ddagger$ & 114 (41.2) & 94 (39.3) & $208(40.3)$ \\
\hline $\mathrm{ESBL}+$ and $\mathrm{MDR}$ & 40 (14.4) & $39(16.3)$ & 79 (15.3) \\
\hline $\mathrm{ESBL}+$ and XDR & $26(9.4)$ & $23(9.6)$ & $49(9.5)$ \\
\hline
\end{tabular}

$\mathrm{ESBL}=$ Enterobacteriaceae; $\mathrm{MDR}=$ multidrug resistant; $\mathrm{XDR}=$ extensively drug resistant.

${ }^{\star}$ E. coli isolates were selectively plated on MacConkey with $1 \mathrm{mg} / \mathrm{mL}$ concentration of ceftriaxone.

† Classified as resistant to three or more classes of antibiotics.

$\neq$ Classified as resistant to five or more classes of antibiotics. 
at home as an exposure associated with nasal carriage of methicillin-resistant Staphylococcus aureus. ${ }^{38}$ On average, households in this study population were roughly $2 \mathrm{~km}$ from the nearest commercial poultry operation. Also, there was an average of 12 facilities within a 5-km radius of each household. Other studies have also hypothesized that animal waste containing $E$. coli is often applied to land surrounding poultry operations and is dispersed in many ways, including through vectors such as houseflies. ${ }^{39}$ Studies have shown associations between small-scale farming as well as companion animal ownership and AMR. A study in northwest coastal Ecuador found that small-scale poultry farming in the community was associated with increased risk of AMR. ${ }^{40}$ Animal ownership among our study population ranged in terms of number of animals owned; approximately half of the households owned between 1 to 20 animals, with a much lower percentage of households owning more than 20 animals. These cutoffs for ranges of animal ownership were determined a priori, based on previous literature and to see the effects of smallscale farming and pet ownership. ${ }^{41}$ Ownership of 11 to 20 animals was found to be associated with XDR E. coli, but the exposure in this particular study did not differentiate between the type or species of animals owned (e.g., livestock versus poultry versus domestic pets). Animals in these communities range from household pets, such as dogs and cats, to food animals including chickens, cattle, and pigs. Culturally, animals, even pets, are primarily kept outside of homes in the study area. In households that owned chickens, it may be that the ones owning fewer chickens may keep them closer to the home or allow them to roam freely, whereas those owning larger numbers may keep them in pens farther away from the house. This behavior could lead to less exposure. Additionally, the lack of animals in the household does not necessarily mean a child is not exposed to animals. The organisms infecting children sometimes come from animals a farther distance away. Previous studies found that children were often carrying $E$. coli similar to animals farther away from where they live. ${ }^{42}$ There is also the potential for misclassification of exposure with classifying animal exposure by ownership because there is a strong chance for exposure regardless of animal ownership through exposures outside the home. Further, there is some evidence of ESBL E. coli colonization among household pets. A previous study in Quito detected the presence of MDR E. coli in dog feces found in local public

TABLE 4

Univariate and multivariate analysis of child and household-level risk factors for colonization with ESBL-E. coli

\begin{tabular}{|c|c|c|c|}
\hline & ESBL positive, $n(\%)$ & Unadjusted OR (95\% Cl) & Adjusted OR $(95 \% \mathrm{Cl})^{*}$ \\
\hline \multicolumn{4}{|l|}{ Caregiver education level } \\
\hline University/college $(n=77)$ & $4(5.2)$ & Ref & Ref \\
\hline High school $(n=472)$ & $53(11.2)$ & $2.30(0.694-7.65)$ & $2.27(0.699-7.39)$ \\
\hline Elementary school $(n=184)$ & $27(14.6)$ & $3.06(0.882-10.6)$ & $3.09(0.895-10.6)$ \\
\hline No formal education $(n=11)$ & 2 (18.2) & $3.54(0.408-30.8)$ & $3.50(0.402-30.4)$ \\
\hline \multicolumn{4}{|l|}{ Wealth index score } \\
\hline Low $(n=184)$ & $18(9.8)$ & Ref & Ref \\
\hline Medium $(n=307)$ & 34 (11.1) & $0.848(0.510-1.41)$ & $0.824(0.497-1.36)$ \\
\hline $\operatorname{High}(n=249)$ & 33 (13.3) & $0.722(0.379-1.37)$ & $0.728(0.383-1.38)$ \\
\hline \multicolumn{4}{|l|}{ Household size } \\
\hline $1-3$ people $(n=177)$ & $18(10.2)$ & Ref & Ref \\
\hline 4-6 people $(n=493)$ & $59(12.0)$ & $1.19(0.667-2.11)$ & $1.16(0.647-2.07)$ \\
\hline$\geq 7$ people $(n=70)$ & $8(11.4)$ & $1.16(0.490-2.75)$ & $1.16(0.459-2.95)$ \\
\hline \multicolumn{4}{|l|}{ Children $<12$ years in household } \\
\hline $0-2(n=633)$ & $76(12.0)$ & Ref & Ref \\
\hline $3-4(n=102)$ & $8(7.8)$ & $0.634(0.285-1.41)$ & $0.595(0.256-1.38)$ \\
\hline $5-7(n=5)$ & $1(20.0)$ & $1.96(0.233-16.5)$ & $1.84(0.186-18.2)$ \\
\hline \multicolumn{4}{|c|}{ Crowding (average no. of people per room) } \\
\hline Low $(0-2.5 ; n=480)$ & $51(10.6)$ & Ref & Ref \\
\hline High $(2.5-8 ; n=260)$ & $34(13.1)$ & $1.28(0.810-2.03)$ & $1.34(0.825-2.16)$ \\
\hline \multicolumn{4}{|c|}{ Treatment of drinking water before consumption } \\
\hline Yes $(n=374)$ & $44(11.8)$ & Ref & Ref \\
\hline No $(n=366)$ & $41(11.2)$ & $0.973(0.637-1.49)$ & $0.911(0.577-1.44)$ \\
\hline \multicolumn{4}{|l|}{ Daycare attendance } \\
\hline No $(n=603)$ & $65(10.8)$ & Ref & Ref \\
\hline Yes $(n=136)$ & $20(14.7)$ & $1.42(0.80-2.50)$ & $1.61(0.909-2.86)$ \\
\hline \multicolumn{4}{|c|}{ Odor due to commercial poultry/livestock } \\
\hline No $(n=575)$ & $67(11.7)$ & Ref & Ref \\
\hline Yes $(n=160)$ & 17 (10.6) & $0.81(0.445-1.47)$ & $0.607(0.319-1.16)$ \\
\hline \multicolumn{4}{|l|}{ Animal ownership } \\
\hline No $(n=255)$ & $22(8.6)$ & Ref & Ref \\
\hline Yes $(n=484)$ & $62(12.8)$ & $1.57(0.926-2.65)$ & $1.64(0.960-2.79)$ \\
\hline \multicolumn{4}{|l|}{ No. of animals in household } \\
\hline $0(n=266)$ & $25(9.4)$ & Ref & Ref \\
\hline $1-10(n=332)$ & $42(12.7)$ & $1.51(0.868-2.622)$ & $1.55(0.889-2.70)$ \\
\hline $11-20(n=65)$ & $8(12.3)$ & $1.49(0.639-3.48)$ & $1.55(0.663-3.64)$ \\
\hline $21-30(n=28)$ & $3(10.7)$ & $1.16(0.320-4.24)$ & $1.29(0.357-4.68)$ \\
\hline $31-40(n=21)$ & 4 (19.0) & $2.82(0.687-7.59)$ & $2.54(0.767-8.40)$ \\
\hline $41-50(n=7)$ & 0 & $0(0)$ & $0(0)$ \\
\hline$>50(n=26)$ & $4(15.4)$ & $1.89(0.581-6.14)$ & $1.05(0.629-6.70)$ \\
\hline
\end{tabular}

$\mathrm{ESBL}=$ Enterobacteriaceae; $\mathrm{Cl}=$ confidence interval; $\mathrm{OR}=$ odds ratio.

${ }^{*}$ Adjusted ORs were obtained from models adjusted for confounding variables. Models and directed acyclic graphs (DAGs) indicating confounding variables can be found in supplemental materials (Supplemental Table 1 and Supplemental Figure 1). 
parks. ${ }^{43}$ A study in Kenya found humans and dogs living in the same area shared genetically similar ESBL E. coli, and another study in Sweden found relatively high rates of ESBL/AmpCproducing Enterobacteriaceae among healthy dogs and cats. ${ }^{44,45}$ A review article looking at studies using the application of advanced genotyping techniques found a number of studies demonstrating transmission of $E$. coli between humans and animals. ${ }^{46}$ In our study, it is possible that increased presence of domestic animals exposes household members to more resistant bacteria carried by either pets or farm animals.

We identified weak relationships among hygiene factors, SES, and crowding and the presence of ESBL, MDR, or XDR $E$. coli in children of Quito, Ecuador. It may be that community-level or regional-level factors, rather than household-level factors, are the main drivers for the spread of AMR. Alternatively, it may be that the microbiological quality of the food and water supply, which was not evaluated in this study, could play a larger role in AMR transmission. Third, Ecuador is considered an upper-middle-income country, and in semirural communities of Quito, water, sanitation and hygiene infrastructure are well developed. Most households had piped water (high-quality water from glacial melt at higher altitude), toilets that drain into sewers, and infrastructure to perform hand hygiene behaviors. This difference in development may also explain these weak relationships. Overall, we did not find statistically significant relationships among indicators of crowding, SES, or improved hygiene practices, and the presence of ESBL E. coli, in both univariate and multivariate analyses. However, we did see several variables trend in the expected direction. Although not significant, high crowding (2.5-8 people per room) did appear to increase the odds of all three antimicrobial resistance outcomes studied. One study found an inverse relationship, more crowded households had lower odds of MDR E. coli. ${ }^{46}$ A study in Hong Kong found that ESBL-producing bacteria was inversely correlated with living space per person: as the square feet per person increased, the colonization index of the family decreased. ${ }^{47}$ A larger household size also appeared to increase the odds of all types of resistance, although relationships were not significant. No clear statistical associations were observed for children in households where the drinking water was treated.

High school-level education of the caregiver, compared with university/college education, and XDR E. coli were found to have a statistically significant relationship; however, the

TABLE 5

Univariate analysis of individual and household-level risk factors for presence of MDR and XDR Escherichia coli

\begin{tabular}{|c|c|c|c|c|}
\hline & MDR positive, $n(\%)$ & MDR unadjusted OR $(95 \% \mathrm{Cl})$ & XDR positive, (n \%) & XDR unadjusted OR (95\% Cl) \\
\hline \multicolumn{5}{|l|}{ Caregiver education level } \\
\hline University/college $(n=77)$ & 25 (32.5) & Ref & $10(13.0)$ & Ref \\
\hline High school $(n=472)$ & $209(44.3)$ & $1.66(1.00-2.74)$ & $>109$ (23.1) & $>2.03(1.01-4.11)$ \\
\hline Elementary school $(n=184)$ & 77 (41.8) & $1.51(0.870-2.62)$ & $41(22.3)$ & $1.93(0.906-4.12)$ \\
\hline No formal education $(n=11)$ & $5(45.5)$ & 0.417 (0.063-2.74) & $1(9.1)$ & $0(0)$ \\
\hline \multicolumn{5}{|l|}{ Wealth index score } \\
\hline Low $(n=184)$ & 67 (36.4) & Ref & $57(23.0)$ & Ref \\
\hline Medium $(n=307)$ & $131(42.7)$ & $0.891(0.635-1.25)$ & $72(23.5)$ & $1.05(0.713-1.55)$ \\
\hline High $(n=249)$ & $114(45.8)$ & $0.674(0.455-0.999)$ & $31(16.8)$ & $0.675(0.413-1.10)$ \\
\hline \multicolumn{5}{|l|}{ Household size } \\
\hline $1-3$ people $(n=177)$ & 70 (39.5) & Ref & $36(20.3)$ & Ref \\
\hline 4-6 people $(n=493)$ & $212(43.0)$ & $1.15(0.807-1.64)$ & $110(22.3)$ & $1.10(0.724-1.66)$ \\
\hline$\geq 7$ people $(n=70)$ & 30 (42.9) & $1.14(0.642-2.04)$ & $14(20.0)$ & $0.971(0.463-1.91)$ \\
\hline \multicolumn{5}{|c|}{ Children under 12 years in household } \\
\hline $0-2(n=633)$ & $272(43.0)$ & Ref & $142(22.4)$ & Ref \\
\hline $3-4(n=102)$ & 37 (36.3) & $0.756(0.490-1.17)$ & $17(16.7)$ & $0.684(0.382-1.22)$ \\
\hline $5-7(n=5)$ & $3(60.0)$ & $2.92(0.336-12.2)$ & $1(20.0)$ & $0.973(0.124-7.66)$ \\
\hline \multicolumn{5}{|c|}{ Crowding (average number of people per room) } \\
\hline Low $(0-2.5 ; n=480)$ & $198(41.3)$ & Ref & $99(20.6)$ & Ref \\
\hline High $(2.5-8 ; n=260)$ & $114(43.8)$ & $1.11(0.822-1.51)$ & $61(23.5)$ & $1.18(0.821-1.70)$ \\
\hline \multicolumn{5}{|c|}{ Treatment of drinking water before consumption } \\
\hline Yes $(n=374)$ & $156(41.7)$ & Ref & $84(23.0)$ & Ref \\
\hline No $(n=366)$ & $156(42.6)$ & $1.05(0.785-1.41)$ & $76(20.3)$ & $1.20(0.847-1.71)$ \\
\hline \multicolumn{5}{|l|}{ Daycare attendance } \\
\hline No $(n=603)$ & $257(42.6)$ & Ref & $133(22.1)$ & Ref \\
\hline Yes $(n=136)$ & $55(40.4)$ & $0.913(0.625-1.34)$ & 27 (19.9) & $0.894(0.561-1.43)$ \\
\hline \multicolumn{5}{|c|}{ Odor due to commercial poultry/livestock } \\
\hline No $(n=575)$ & $238(41.4)$ & Ref & $111(19.3)$ & Ref \\
\hline Yes $(n=160)$ & $72(45.0)$ & $1.15(0.799-1.64)$ & 48 (30.0) & $1.74(1.16-2.60)$ \\
\hline \multicolumn{5}{|l|}{ Animal ownership } \\
\hline No $(n=255)$ & 100 (39.2) & Ref & 48 (18.8) & Ref \\
\hline Yes $(n=484)$ & 211 (43.6) & $1.19(0.868-1.62)$ & $111(22.9)$ & $1.26(0.860-1.86)$ \\
\hline \multicolumn{5}{|l|}{ No. of animals in household } \\
\hline $0(n=266)$ & $106(39.8)$ & Ref & $51(19.2)$ & Ref \\
\hline $1-10(n=332)$ & $143(43.1)$ & $1.18(0.842-1.66)$ & $76(22.9)$ & $1.26(0.835-1.89)$ \\
\hline $11-20(n=65)$ & $31(47.7)$ & $1.42(0.837-2.42)$ & $20(30.8)$ & 1.87 (1.02-3.44) \\
\hline $21-30(n=28)$ & $12(42.9)$ & $1.16(0.532-2.53)$ & $4(14.3)$ & $0.722(0.247-2.11)$ \\
\hline $31-40(n=21)$ & 9 (42.9) & $1.14(0.454-2.85)$ & $3(14.3)$ & $0.672(0.189-2.40)$ \\
\hline $41-50(n=7)$ & $5(71.4)$ & 3.87 (0.670-22.32) & 1 (14.3) & $0.776(0.093-6.50)$ \\
\hline$>50(n=26)$ & $10(38.5)$ & $0.962(0.405-2.29)$ & $6(23.1)$ & $1.26(0.475-3.35)$ \\
\hline
\end{tabular}


significance was lost once the model was adjusted for SES. Studies describing the impact that education has on AMR have demonstrated conflicting results. ${ }^{16,48}$ A study of anthropological factors and worldwide antibiotic resistance found that higher education was significantly associated with increased antimicrobial resistance, potentially due to increased SES and ability to purchase more expensive broad-spectrum antibiotics. ${ }^{16}$ Similarly, a study of antibiotic use in Sweden found that the use increased as parental education increased. ${ }^{49}$ Increased antibiotic consumption is a risk factor for AMR, so it is feasible that education level could influence antibiotic consumption. Education levels appear to affect antimicrobial resistance in high-income countries, but the effect is not as clear in low- and middle-income countries. ${ }^{18}$ In our study, we saw a different trend. We found that an intermediate education level, high school education, was significantly associated with XDR E. coli carriage, but the relationship was not significant when adjusted for confounding.

We also found a high wealth index score was found to be associated with the presence of MDR E. coli, but this relationship became insignificant once the model was adjusted for confounders, education, and household size. Socioeconomic status has been shown to be associated with AMR, but there is conflicting evidence on the direction of the relationship. A study on community-acquired resistance in India found a negative relationship between the prevalence of ESBL-producing organisms among the study population and income. ${ }^{50}$ Other studies have found the opposite effect, including a study of antimicrobial resistance in Peru that found an increased odds ratio for AMR among children of wealthier families; another found that not owning one's home, a component of our wealth index, increased the risk of carriage of resistant E. coli. ${ }^{48,51}$

In this study, we found no significant association between child daycare attendance and any antimicrobial resistance outcomes. A relatively low number of children (13.9\% cycle 1 , $23.0 \%$ cycle 2 ) were reported to regularly attend daycare in our study, which may have led to an inability to measure an association. Among those who reported daycare attendance, only $14.7 \%$ carried ESBL-producing E. coli. However, we did

TABLE 6

Multivariate analysis of individual and household-level risk factors for presence of MDR and XDR Escherichia coli

\begin{tabular}{|c|c|c|c|c|}
\hline & MDR positive, n (\%) & MDR adjusted OR $(95 \% \mathrm{Cl})^{\star}$ & XDR positive, (n \%) & XDR adjusted OR $(95 \% \mathrm{Cl})^{\star}$ \\
\hline \multicolumn{5}{|l|}{ Caregiver education level } \\
\hline University/college $(n=77)$ & 25 (32.5) & Ref & $10(13.0)$ & Ref \\
\hline High school $(n=472)$ & 209 (44.3) & $1.60(0.964-2.67)$ & $109(23.1)$ & $1.93(0.953-3.92)$ \\
\hline Elementary school $(n=184)$ & 77 (41.8) & 1.49 (0.855-2.60) & 41 (22.3) & $1.86(0.876-3.96)$ \\
\hline No formal education $(n=11)$ & $5(45.5)$ & $0.410(0.061-2.76)$ & $1(9.1)$ & $0(0)$ \\
\hline \multicolumn{5}{|l|}{ Wealth index score } \\
\hline Low $(n=184)$ & 67 (36.4) & Ref & $57(23.0)$ & Ref \\
\hline Medium $(n=307)$ & $131(42.7)$ & $0.882(0.627-1.24)$ & $72(23.5)$ & $1.03(0.700-1.53)$ \\
\hline High $(n=249)$ & $114(45.8)$ & 0.702 (0.472-1.05) & 31 (16.8) & $0.701(0.426-1.15)$ \\
\hline \multicolumn{5}{|l|}{ Household size } \\
\hline 1-3 people $(n=177)$ & 70 (39.5) & Ref & $36(20.3)$ & Ref \\
\hline 4-6 people $(n=493)$ & $212(43.0)$ & $1.15(0.792-1.66)$ & $110(22.3)$ & $1.10(0.718-1.69)$ \\
\hline$\geq 7$ people $(n=70)$ & 30 (42.9) & $1.18(0.622-2.25)$ & $14(20.0)$ & $1.03(0.46-2.30)$ \\
\hline \multicolumn{5}{|c|}{ Children under 12 years per household } \\
\hline $0-2(n=633)$ & $272(43.0)$ & Ref & $142(22.4)$ & Ref \\
\hline $3-4(n=102)$ & $37(36.3)$ & $0.710(0.445-1.13)$ & 17 (16.7) & $0.646(0.341-1.22)$ \\
\hline $5-7(n=5)$ & $3(60.0)$ & $1.91(0.269-13.5)$ & 1 (20.0) & $0.989(0.112-8.71)$ \\
\hline \multicolumn{5}{|c|}{ Crowding (average number of people per room) } \\
\hline Low $(0-2.5$ people) $(n=480)$ & $198(41.3)$ & Ref & $99(20.6)$ & Ref \\
\hline High (2.5-8 people) $(n=260)$ & $114(43.8)$ & $1.19(0.856-1.65)$ & $61(23.5)$ & $1.23(0.852-1.85)$ \\
\hline \multicolumn{5}{|c|}{ Treatment of drinking water before consumption } \\
\hline Yes $(n=374)$ & $156(41.7)$ & Ref & $84(23.0)$ & Ref \\
\hline No $(n=366)$ & $156(42.6)$ & $1.02(0.746-1.40)$ & $76(20.3)$ & $1.18(0.816-1.72)$ \\
\hline \multicolumn{5}{|l|}{ Daycare attendance } \\
\hline No $(n=603)$ & $257(42.6)$ & Ref & $133(22.1)$ & Ref \\
\hline Yes $(n=136)$ & $55(40.4)$ & $1.02(0.670-1.55)$ & 27 (19.9) & $0.999(0.583-1.71)$ \\
\hline \multicolumn{5}{|c|}{ Odor due to commercial poultry/livestock } \\
\hline No $(n=575)$ & $238(41.4)$ & Ref & 111 (19.3) & Ref \\
\hline Yes $(n=160)$ & $72(45.0)$ & $0.884(0.662-1.49)$ & 48 (30.0) & $1.72(1.11-2.66)$ \\
\hline \multicolumn{5}{|l|}{ Animal ownership } \\
\hline No $(n=255)$ & 100 (39.2) & Ref & 48 (18.8) & Ref \\
\hline Yes $(n=484)$ & $211(43.6)$ & $1.25(0.911-1.71)$ & 111 (22.9) & 1.33 (0.896-1.97) \\
\hline \multicolumn{5}{|l|}{ No. animals per household } \\
\hline $0(n=266)$ & 106 (39.8) & Ref & $51(19.2)$ & Ref \\
\hline $1-10(n=332)$ & $143(43.1)$ & $1.22(0.870-1.72)$ & $76(22.9)$ & $1.29(0.853-1.94)$ \\
\hline $11-20(n=65)$ & $31(47.7)$ & 1.49 (0.872-2.56) & $20(30.8)$ & $1.94(1.05-3.60)$ \\
\hline $21-30(n=28)$ & 12 (42.9) & $1.31(0.596-2.87)$ & 4 (14.3) & $0.823(0.282-2.41)$ \\
\hline $31-40(n=21)$ & 9 (42.9) & 1.26 (0.499-3.19) & $3(14.3)$ & 0.759 (0.214-2.70) \\
\hline $41-50(n=7)$ & $5(71.4)$ & 4.09 (0.678-24.7) & $1(14.3)$ & 0.809 (0.100-6.56) \\
\hline$>50(n=26)$ & $10(38.5)$ & 1.05 (0438-2.54) & $6(23.1)$ & 1.39 (0.518-3.75) \\
\hline
\end{tabular}


observe an increase in the odds of ESBL $E$. coli carriage among children who attended daycare. This trend was less pronounced for MDR and XDR E. coli carriage. Previous studies from Sweden and the Netherlands have documented an association between daycare attendance and ESBLproducing Enterobacteriaceae carriage among preschool children. ${ }^{52-54}$ van den Bunt et al. identified attending a daycare center as the only significant risk factor for ESBL/AmpC prevalence among Dutch children between 2013 and $2015 .^{52} \mathrm{~A}$ study in the Netherlands found the carriage rate of $2.9 \%$ for ESBL-producing Enterobacteriaceae among healthy children enrolled in the study and indicated that transmission most likely occurred at preschools rather than between household members. Similar risks are present in daycares in Scandinavia as in LMICs, but there could be differences in exposure level between them.

This study has some limitations. First, the limited number of ESBL, MDR, and XDR E. coli positive children may have limited our ability to detect statistically significant associations between our exposure variables and outcomes. Although survey participation was high, the presence of ESBL among children in these communities ( $\sim 11 \%$ of children) may have been too low to ascertain associations with exposure variables on an individual level. Second, survey responses were selfreported, which has the potential to introduce recall and interviewer bias into the study - in particular, for questions assessing drinking-water treatment and household assets. This could make it difficult to determine the true exposure and its association with AMR. Third, the well-developed WaSH infrastructure in Ecuador, as described earlier, could also be limitation. In low-income countries or other communities in more rural parts of Ecuador, where WaSH infrastructure is more limited, one may be able to observe an association between WaSH characteristics and AMR. There are many potential pathways of exposure that we were not able to capture in this household-level analysis that may be captured by community-level studies. Study participants likely could have been exposed to reservoirs of antimicrobial-resistant bacteria present in the community, through the food supply for example, which may not allow differences to be captured on a household level. Wastewater in Quito, which contains human and animal waste, goes into the environment untreated. This surface water contamination may affect the microbiological quality of edible crops irrigated with surface water. Fourth, the absence of clinical data, specifically relating to colonization of enteric pathogens, antibiotic prescription, and use and previous diarrhea, is a limitation. The connection between antibiotic use for a variety of reasons, including diarrhea, and antimicrobial resistance is an important factor that may influence the results of this study.

Overall, our study identified a limited number of associations between exposure variables of interest and the risk of AMR in children in Ecuador. Animal ownership and proximity to commercial poultry or livestock operations may be important predictors of community-acquired multidrug resistance. We found little evidence of associations between many socioeconomic and WaSH variables, particularly hygiene and crowding, and AMR outcomes. Future studies could use a variety of communities to ensure community-level variability in exposure variables and develop a better estimate of the relationship between socioeconomic and environmental exposures and AMR. Similar studies could be done in communities that have more divergent levels of WaSH infrastructure to determine the true effect on WaSH on AMR. Lastly, in future subanalyses using the data collected from this study, an analysis of households that remained in cycle 2 from cycle 1 would be useful, as well as examining the potential changes in exposure variables in households from cycle 1 to cycle 2 .

Received May 22, 2020. Accepted for publication April 12, 2021.

Published online July 19, 2021.

Note: Supplemental table and figure appear at www.ajtmh.org.

Acknowledgment: We greatly appreciate the assistance of Gabriela Heredia Arias, Paul Barahona Bonilla, Deysi Parrales Chicaiza, Anahí Flores Enriquez, Cristian Garzón, Joel Barahona Garzón, Valeria Garzón, Barbara Baque Pisco, and Rommel Guevara Santander, as well as the communities involved in the study and our colleagues in the Microbiology Institute at the Universidad San Francisco de Quito, in conducting this research. We also greatly appreciate the assistance and support from the Center for Global Public Health (CGPH) and the Henry Wheeler Center for Emerging and Neglected Diseases (CEND) at the University of California Berkeley.

Financial support: Research reported in this publication was supported by the National Institutes of Health under award no. R01Al135118.

Disclaimer: The content is solely the responsibility of the authors and does not necessarily represent the official views of the National Institutes of Health. The funders had no role in study design, data collection and interpretation, or the decision to submit the work for publication.

Authors' addresses: Kathleen M. Kurowski and Rachel Marusinec, Division of Infectious Diseases and Vaccinology, University of California, Berkeley School of Public Health, Berkeley, CA, E-mails: kathleen kurowski@berkeley.edu and rachel_marusinec@berkeley.edu. Heather K. Amato and Jay P. Graham, Division of Environmental Health Sciences, University of California, Berkeley School of Public Health, Berkeley, CA, E-mail: heather_amato@berkeley.edu and jay. graham@berkeley.edu. Carlos Saraiva-Garcia, Fernanda Loayza, Liseth Salinas, and Gabriel Trueba, Instituto de Microbiología, Colegio de Ciencias Biológicas y Ambientales, Universidad San Francisco de Quito, Quito, Ecuador, E-mails: hsaraiva@usfq.edu.ec, mfloayzav@ usfq.edu.ec, Isalinas2@estud.usfq.edu.ec, and gtrueba@usfq.edu.ec.

\section{REFERENCES}

1. Centers for Disease Control and Prevention, 2019. Antibiotic Resistance Threats in the United States. Available at: https:// www.cdc.gov/drugresistance/pdf/threats-report/2019-arthreats-report-508.pdf. Accessed January 15, 2020.

2. de Kraker MEA, Davey PG, Grundmann H, 2011. Mortality and hospital stay associated with resistant Staphylococcus aureus and Escherichia coli bacteremia: estimating the burden of antibiotic resistance in Europe. PLoS Med 8: e1001104.

3. Centers for Disease Control and Prevention, 2016. Antibiotic/antimicrobial Resistance: Biggest Threats. Available at: https:// www.cdc.gov/drugresistance/biggest-threats.html. Accessed January 15, 2020.

4. Janvier F, Mérens A, Delaune D, Soler C, Cavallo J-D, 2011. Fecal carriage of third-generation cephalosporins-resistant Enterobacteriaceae in asymptomatic young adults: evolution between 1999 and 2009. Pathol Biol (Paris) 59: 97-101.

5. Holmes AH, Moore LSP, Sundsfjord A, Steinbakk M, Regmi S, Karkey A, Guerin PJ, Piddock LJV, 2016. Understanding the mechanisms and drivers of antimicrobial resistance. Lancet 387: 176-187.

6. Murray TS, Peaper DR, 2015. The contribution of extendedspectrum $\beta$-lactamases to multidrug-resistant infections in children. Curr Opin Pediatr 27: 124-131.

7. Megged O, 2014. Extended-spectrum $\beta$-lactamase-producing bacteria causing community-acquired urinary tract infections in children. Pediatr Nephrol 29: 1583-1587.

8. Laupland KB, Church DL, Vidakovich J, Mucenski M, Pitout JDD, 2008. Community-onset extended-spectrum $\beta$-lactamase 
(ESBL) producing Escherichia coli: importance of international travel. J Infect 57: 441-448.

9. Blyth DM, Mende K, Maranich AM, Beckius ML, Harnisch KA, Rosemann CA, Zera WC, Murray CK, Akers KS, 2016. Antimicrobial resistance acquisition after international travel in U.S. travelers. Trop Dis Travel Med Vaccines 2: 4.

10. Tängdén $T$, Cars $O$, Melhus $A$, Löwdin E, 2010. Foreign travel is a major risk factor for colonization with Escherichia coli producing CTX-M-type extended-spectrum beta-lactamases: a prospective study with Swedish volunteers. Antimicrob Agents Chemother 54: 3564-3568.

11. Vikesland P, Garner E, Gupta S, Kang S, Maile-Moskowitz A, Zhu $\mathrm{N}, 2019$. Differential drivers of antimicrobial resistance across the world. Acc Chem Res 52: 916-924.

12. Finley $\mathrm{RL}$ et al., 2013. The scourge of antibiotic resistance: the important role of the environment. Clin Infect Dis 57: 704-710.

13. Bonelli RR, Moreira BM, Picão RC, 2014. Antimicrobial resistance among Enterobacteriaceae in South America: history, current dissemination status and associated socioeconomic factors. Drug Resist Updat 17: 24-36.

14. Singer RS, Finch R, Wegener HC, Bywater R, Walters J, Lipsitch $M, 2003$. Antibiotic resistance-the interplay between antibiotic use in animals and human beings. Lancet Infect Dis 3: 47-51.

15. Dohmen W, Bonten MJM, Bos MEH, van Marm S, Scharringa J, Wagenaar JA, Heederik DJJ, 2015. Carriage of extendedspectrum $\beta$-lactamases in pig farmers is associated with occurrence in pigs. Clin Microbiol Infect 21: 917-923.

16. Collignon P, Beggs JJ, Walsh TR, Gandra S, Laxminarayan R, 2018. Anthropological and socioeconomic factors contributing to global antimicrobial resistance: a univariate and multivariable analysis. Lancet Planet Health 2: e398-e405.

17. Kraemer SA, Ramachandran A, Perron GG, 2019. Antibiotic pollution in the environment: from microbial ecology to public policy. Microorganisms 7: 180.

18. Alividza V, Mariano V, Ahmad R, Charani E, Rawson TM, Holmes AH, Castro-Sánchez E, 2018. Investigating the impact of poverty on colonization and infection with drug-resistant organisms in humans: a systematic review. Infect Dis Poverty 7: 76.

19. Nellums LB, Thompson H, Holmes A, Castro-Sánchez E, Otter JA, Norredam M, Friedland JS, Hargreaves S, 2018. Antimicrobial resistance among migrants in Europe: a systematic review and meta-analysis. Lancet Infect Dis 18: 796-811.

20. Bruinsma N, Hutchinson JM, van den Bogaard AE, Giamarellou H, Degener J, Stobberingh EE, 2003. Influence of population density on antibiotic resistance. J Antimicrob Chemother 51: 385390.

21. World Health Organization, 2020. Antimicrobial Resistance: An Emerging Water, Sanitation and Hygiene Issue. Geneva, Switzerland WHO. Available at: http://www.who.int/water_ sanitation_health/publications/antimicrobial-resistance/en/. Accessed February 25, 2020.

22. Nadimpalli ML et al., 2020. Urban informal settlements as hotspots of antimicrobial resistance and the need to curb environmental transmission. Nat Microbiol 5: 787-795.

23. Ramay BM et al., 2020. Antibiotic use and hygiene interact to influence the distribution of antimicrobial-resistant bacteria in lowincome communities in Guatemala. Sci Rep 10: 13767.

24. Ngure FM et al., 2013. Formative research on hygiene behaviors and geophagy among infants and young children and implications of exposure to fecal bacteria. Am J Trop Med Hyg 89: 709-716.

25. Salinas L, Cárdenas $P$, Johnson TJ, Vasco K, Graham J, Trueba G, 2019. Diverse commensal Escherichia coli clones and plasmids disseminate antimicrobial resistance genes in domestic animals and children in a semirural community in Ecuador. MSphere 4 e00316-19.

26. Boonyasiri A, Tangkoskul T, Seenama C, Saiyarin J, Tiengrim S, Thamlikitkul V, 2014. Prevalence of antibiotic resistant bacteria in healthy adults, foods, food animals, and the environment in selected areas in Thailand. Pathog Glob Health 108: 235-245.

27. Hammerum AM et al., 2014. Characterization of extendedspectrum $\beta$-lactamase (ESBL)-producing Escherichia coli obtained from Danish pigs, pig farmers and their families from farms with high or no consumption of third- or fourth- generation cephalosporins. I Antimicrob Chemother 69: 2650-2657.

28. Lautenbach E, Bilker WB, Tolomeo P, Maslow JN, 2008. Impact of diversity of colonizing strains on strategies for sampling Escherichia coli from fecal specimens. J Clin Microbiol 46: 3094-3096.

29. Tandé D, Boisramé-Gastrin S, Münck MR, Héry-Arnaud G, Gouriou S, Jallot N, Nordmann P, Naas T, 2010. Intrafamilial transmission of extended-spectrum- $\beta$-lactamase-producing Escherichia coli and Salmonella enterica Babelsberg among the families of internationally adopted children. $J$ Antimicrob Chemother 65: 859-865.

30. Clinical and Laboratory Standards Institute, M100. Performance Standards for Antimicrobial Susceptibility Testing, 30th edition. Available at: https://clsi.org/standards/products/microbiology/ documents/m100/. Accessed February 25, 2020.

31. Rupp ME, Fey PD, 2003. Extended spectrum $\beta$-lactamase (ESBL)-producing enterobacteriaceae. Drugs 63: 353-365.

32. European Committee on Antimicrobial Susceptibility Testing, 2017. EUCAST Guidelines for Detection of Resistance Mechanisms and Specific Resistances of Clinical and/or Epidemiological Importance, Version 2.0. Available at: https://www.eucast. org/fileadmin/src/media/PDFs/EUCAST_files/Resistance mechanisms/EUCAST_detection_of_resistance_mechanisms_ 170711.pdf.

33. Howe LD et al., 2012. Measuring socio-economic position for epidemiological studies in low- and middle-income countries: a methods of measurement in epidemiology paper. Int $J$ Epidemiol 41: 871-886.

34. Filmer D, Pritchett LH, 2001. Estimating wealth effects without expenditure data-or tears: an application to educational enrollments in states of India. Demography 38: 115-132.

35. Nadimpalli ML et al., 2018. Face mask use and persistence of livestock-associated Staphylococcus aureus nasal carriage among industrial hog operation workers and household contacts, USA. Environ Health Perspect 126: 127005.

36. Prendergast AJ et al., 2019. Putting the "A" into WaSH: a call for integrated management of water, animals, sanitation, and hygiene. Lancet Planet Health 3: e336-e337.

37. Lowenstein C, Waters WF, Roess A, Leibler JH, Graham JP, 2016. Animal husbandry practices and perceptions of zoonotic infectious disease risks among livestock keepers in a rural parish of Quito, Ecuador. Am J Trop Med Hyg 95: 1450-1458.

38. Schinasi $L$ et al., 2014. A case control study of environmental and occupational exposures associated with methicillin resistant Staphylococcus aureus nasal carriage in patients admitted to a rural tertiary care hospital in a high density swine region. Environ Health 13: 54

39. Lindeberg YL, Egedal K, Hossain ZZ, Phelps M, Tulsiani S, Farhana I, Begum A, Jensen PKM, 2018. Can Escherichia coli fly? The role of flies as transmitters of $E$. coli to food in an urban slum in Bangladesh. Trop Med Int Health 23: 2-9.

40. Braykov NP et al., 2016. Antibiotic resistance in animal and environmental samples associated with small-scale poultry farming in northwestern Ecuador. MSphere 1: e00021-000215.

41. Butzin-Dozier Z, Waters WF, Baca M, Vinueza RL, Saraiva-Garcia C, Graham J, 2020. Assessing upstream determinants of antibiotic use in small-scale food animal production through a simulated client method. Antibiotics (Basel) 10: 2.

42. Liseth S, Fernanda L, Paúl C, Carlos S, Johnson TJ, Heather A, Graham JP, Gabriel T, 2021. Environmental spread of extended spectrum beta-lactamase (ESBL) producing Escherichia coli and ESBL genes among children and domestic animals in Ecuador. Environ Health Perspect 129: 027007.

43. Ortega-Paredes D, Haro M, Leoro-Garzón P, Barba P, Loaiza K, Mora F, Fors M, Vinueza-Burgos C, Fernández-Moreira E, 2019. Multidrug-resistant Escherichia coli isolated from canine faeces in a public park in Quito, Ecuador. J Glob Antimicrob Resist 18: 263-268.

44. Albrechtova K, Dolejska M, Cizek A, Tausova D, Klimes J, Bebora L, Literak I, 2012. Dogs of nomadic pastoralists in northern Kenya are reservoirs of plasmid-mediated cephalosporin- and quinolone-resistant Escherichia coli, including pandemic clone B2-O25-ST131. Antimicrob Agents Chemother 56: 4013-4017. 
45. Hordijk J, Schoormans A, Kwakernaak M, Duim B, Broens E, Dierikx C, Mevius D, Wagenaar JA, 2013. High prevalence of fecal carriage of extended spectrum $\beta$-lactamase/ AmpC-producing Enterobacteriaceae in cats and dogs. Front Microbiol 4: 242.

46. Loayza F, Graham JP, Trueba G, 2020. Factors obscuring the role of $E$. coli from domestic animals in the global antimicrobial resistance crisis: an evidence-based review. Int J Environ Res Public Health 17: 3061

47. Seidman JC, P Anitha K, Kanungo R, Bourgeois AL, Coles CL, 2009. Risk factors for antibiotic-resistant $E$. coli in children in a rural area. Epidemiol Infect 137: 879-888.

48. Lo W-U, Ho P-L, Chow K-H, Lai EL, Yeung F, Chiu SS, 2010. Fecal carriage of CTXM type extended-spectrum beta-lactamaseproducing organisms by children and their household contacts. $J$ Infect 60: 286-292.

49. Kristiansson C, Grape M, Gotuzzo E, Samalvides F, Chauca J, Larsson M, Bartoloni A, Pallecchi L, Kronvall G, Petzold M, 2009. Socioeconomic factors and antibiotic use in relation to antimicrobial resistance in the Amazonian area of Peru. Scand $J$ Infect Dis 41: 303-312.

50. Mangrio E, Wremp A, Moghaddassi M, Merlo J, Bramhagen A-C, Rosvall M, 2009. Antibiotic use among 8-month-old children in
Malmö, Sweden-in relation to child characteristics and parental sociodemographic, psychosocial and lifestyle factors. BMC Pediatr 9: 31.

51. Alsan M, Kammili N, Lakshmi J, Xing A, Khan A, Rani M, Kolli P, Relman DA, Owens DK, 2018. Poverty and communityacquired antimicrobial resistance with extended-spectrum $\beta$-lactamase-producing organisms, Hyderabad, India. Emerg Infect Dis 24: 1490-1496.

52. Kalter HD, Gilman RH, Moulton LH, Cullotta AR, Cabrera L, Velapatiño B, 2010. Risk factors for antibiotic-resistant Escherichia coli carriage in young children in Peru: community-based cross-sectional prevalence study. Am J Trop Med Hyg 82: 879888.

53. van den Bunt G, Liakopoulos A, Mevius DJ, Geurts Y, Fluit AC, Bonten MJM, Mughini-Gras L, van Pelt W, 2017. ESBL/ AmpC-producing Enterobacteriaceae in households with children of preschool age: prevalence, risk factors and co-carriage. $J$ Antimicrob Chemother 72: 589-595.

54. Kaarme J, Molin Y, Olsen B, Melhus Å, 2013. Prevalence of extended-spectrum beta-lactamase-producing Enterobacteriaceae in healthy Swedish preschool children. Acta Paediatr 102: 655-660. 